\title{
Performance Indicators for Benchmarking Solar Thermochemical Fuel Processes and Reactors
}

\author{
Brendan Bulfin ${ }^{1 *}$, Miguel Miranda ${ }^{2}$ and Aldo Steinfeld ${ }^{1}$ \\ ${ }^{1}$ Departoment of Mechanical and Process Engineering, ETH Zurich, Zurich, Switzerland, ${ }^{2}$ National Laboratory of Energy and \\ Geology (LNEG), Lisbon, Portugal
}

Concentrated solar energy offers a source for renewable high-temperature process heat that can be used to efficiently drive endothermic chemical processes, converting the entire spectrum of solar radiation into chemical energy. In particular, solar-driven thermochemical processes for the production of fuels include reforming of methane and other hydrocarbons, gasification of biomass, coal, and other carbonaceous feedstock, and metal oxide redox cycles for splitting $\mathrm{H}_{2} \mathrm{O}$ and $\mathrm{CO}_{2}$. A notable issue in the development of these processes and their associated solar reactors is the lack of consistent reporting methods for experimental demonstrations and modelling studies, which complicates the benchmarking of the corresponding technologies. In this work we formulate dimensionless performance indicators based on mass and energy balances of

Edited by:

Thomas Alan Adams, McMaster University, Canada

Reviewed by: Jonathan Scheffe, University of Florida, United States Srirat Chuayboon, King Mongkut's Institute of Technology Ladkrabang, Thailand

${ }^{*}$ Correspondence: Brendan Bulfin bulfinb@ethz.ch

Specialty section: This article was submitted to Process and Energy Systems Engineering, a section of the journal Frontiers in Energy Research

Received: 08 March 2021 Accepted: 06 July 2021

Published: 21 July 2021

Citation:

Bulfin B, Miranda M and Steinfeld A (2021) Performance Indicators for Benchmarking Solar Thermochemical

Fuel Processes and Reactors.

Front. Energy Res. 9:677980. doi: 10.3389/fenrg.2021.677980 such reacting systems, namely: energy efficiency, conversion extent, selectivity, and yield. Examples are outlined for the generic processes mention above. We then provide guidelines for reporting on such processes and reactors and suggest performance benchmarking on four key criteria: energy efficiency, conversion extent, product selectivity, and performance stability.

Keywords: concentrated solar power, solar fuels and chemicals, solar reactors, benchmarking, thermochemical processes

\section{INTRODUCTION}

Concentrated solar power plants have been established for large-scale renewable power generation in areas with high direct normal irradiance (DNI). These plants convert the entire spectrum of DNI into high-temperature heat, which in turn is used by a heat engine to generate electricity. Alternatively, heat can be used to drive endothermic chemical processes (Romero and Steinfeld, 2012; Yadav and Banerjee 2016; Rodat et al., 2020), converting solar energy into chemical energy, with the chemical products acting as energy carriers. A promising application in this area is the production of solar fuels. In particular, syngas-a mixture of $\mathrm{H}_{2}$ and $\mathrm{CO}-$ can be produced via a number of routes as illustrated in Figure 1, and further processed to drop-in transportation fuels such as gasoline and kerosene via established gas-to-liquid technologies (Steinfeld 2012; Agrafiotis et al., 2015). Examples of thermochemical processes for solar fuels production include the gasification of biomass, coal, and other carbonaceous feedstock (Nzihou et al., 2012; Piatkowski et al., 2011, Loutzenhiser and Muroyama 2017, Abanades et al., 2021), reforming of hydrocarbons (Agrafiotis et al., 2014; Sheu et al., 2015), and thermochemical redox cycles for splitting $\mathrm{H}_{2} \mathrm{O}$ and $\mathrm{CO}_{2}$ (Romero and Steinfeld, 2012; Lu et al., 2019; Boretti 2021). The study of these solar driven chemical processes is a growing field of research (Kodama 2003; 


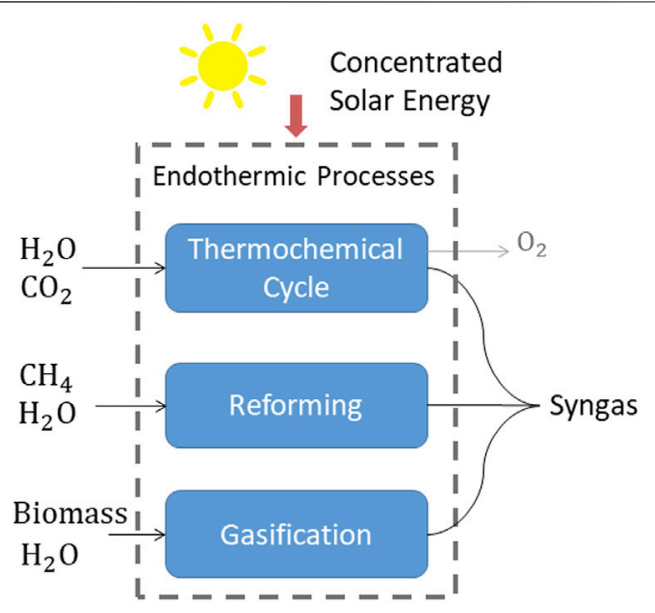

FIGURE 1 | Main process routes for the solar thermochemical production of syngas-a mixture of $\mathrm{H}_{2}$ and $\mathrm{CO}$ that can be further processed to drop-in transportation fuels.

Steinfeld 2014; Mao et al., 2020) with an increasing rate of publications in recent years (Safari and Dincer 2020).

The solar reactor for effecting these processes is the key component and its performance can be the deciding factor in assessing its technical and economic feasibility. Thus, when reporting on the $\mathrm{R} \& \mathrm{D}$ of such reactors it is beneficial to follow standard conventions and procedures to facilitate benchmarking progress.

A generic solar thermochemical reactor can be defined as a system with both an energy and mass flow input (see Figure 2), with a thermochemical transformation consuming energy in the form of heat and converting chemical species. It is convenient in chemical engineering to define dimensionless parameters to describe the energy and mass balances which are independent of scale and process, and can be used as performance indicators to benchmark the system. These are the energy efficiency for the energy balance, and the conversion extent, selectivity and yield for the mass balance. In addition, we are interested in the stability of the process, i.e., its performance over time. All of these aspects will affect the investment capital and operating cost of any scaled up fuel production process. In an opinion article in Advanced Science Views, Ozin highlighted the importance of reporting all of these performance indicators to assess the feasibility of renewable fuel production technologies (Ozin 2018), and notes that seldom are all four: conversion, selectivity, efficiency and stability, reported on. When they are reported on, the definitions of these parameters often vary, in particular for the efficiency, but also for standard chemical process parameters such as selectivity and yield. This article aims to tackle these issues by providing clear protocols and definitions of the dimensionless parameters that can be used as performance indicators for reporting on solar fuel reactors. To do this we propose a standardized efficiency definition, and outline the already standardized chemical process parameters of conversion

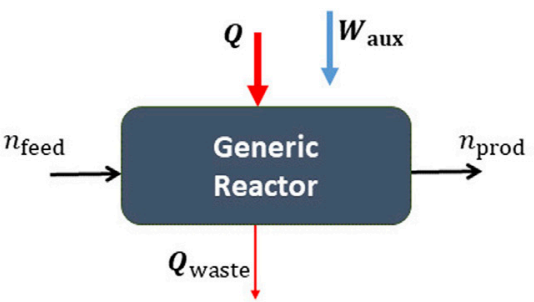

FIGURE 2 | Generic thermochemical reactor with a feedstock $\boldsymbol{n}_{\text {feed }}$ (moles or molar flow rates), a product stream $\boldsymbol{n}_{\text {prod, }}$ a heat input $\boldsymbol{Q}$, a waste heat output $\boldsymbol{Q}_{\text {waste }}$, and some auxiliary work associated with operating the reactor $\boldsymbol{W}_{\text {aux }}$. The heat input is supplied by concentrated solar energy.

extent, selectivity and yield. Examples for applying them to the solar thermochemical processes shown in Figure 1 are provided.

\section{ENERGY EFFICIENCY}

Consider a generic thermochemical reactor as illustrated in Figure 2, which has a feedstock input, a product output, energy inputs in the form of heat and auxiliary work, and waste heat output. To illustrate the definitions, we consider a batch process (or an integral over time of a continuous process) and define efficiencies in terms of the number of moles and quantities of heat and work supplied. For a continuous process molar flow rates, and heat and work flow rates can also be used. We can draw a boundary around the reactor illustrated in Figure $\mathbf{2}$ and treat it as our system. The heat input $Q$ is assumed to be provided by concentrated solar energy, either by direct solar irradiation or by using an indirect method of heat transfer from a solar receiver via heat transfer media. The waste heat can include radiation, conduction, and convection losses, and unrecovered sensible and latent heat in the reaction products and materials of construction. The auxiliary work $W_{\text {aux }}$ is the additional work that is required for the operation of the reactor, for example pumping work to overcome pressure drops or to operate at vacuum/high pressures or the energy required to separate undesired products or the inert gas that is consumed during the process.

We set two criteria for the energy efficiency definition, namely: i) it should reflect the fraction of the supplied energy which is available in the produced fuel, and ii) it should always take a value between zero and one to emphasize the conservation of energy, $\eta \in(0,1)$. A generic energy efficiency can thus be defined as,

$$
\eta=1-\frac{Q_{\text {waste }}}{E_{\text {total }}}
$$

where $E_{\text {total }}=Q+W_{\text {aux }}$, is the total energy supplied to the system and $Q_{\text {waste }}$ is the heat that leaves the system to the surroundings unused. Evidently, $\eta$ should always have a value between 0 and 1 using Eq. 1, unless some component of the supplied energy is 
TABLE 1 | Efficiency definitions in the literature, with the process type, the type of efficiency equation used, whether they use LHV or HHV, and if they include auxiliary work directly or convert it to heat.

\begin{tabular}{|c|c|c|c|c|}
\hline References & Process & Equation $^{a}$ & LHV/HHV & $W_{\text {aux }} / Q_{\text {aux }}$ \\
\hline Bhosale et al. (2017) & Thermochemical cycle & (5) or (6) & $\mathrm{HHV}$ & Q \\
\hline Bhosale (2019) & Thermochemical cycle & (5) or (6) & $\mathrm{HHV}$ & $Q$ \\
\hline Binnoti et al. (2017) & Thermochemical cycle & (5) or (6) & $\mathrm{HHV}$ & Q \\
\hline Bulfin et al. (2016) & Thermochemical cycle & (5) or (6) & $\mathrm{HHV}$ & $Q$ \\
\hline Chuayboon et al. (2019) & Gasification & (6) & LHV & - \\
\hline Chuayboon et al. (2019a) & Reforming & Other & LHV & - \\
\hline Falter (2017) & Thermochemical cycle & (5) or (6) & $\mathrm{HHV}$ & $Q$ \\
\hline Falter and Pitz-Paal, (2017) & Thermochemical cycle & (5) or (6) & $\mathrm{HHV}$ & Q \\
\hline Foshheim et al. (2019) & Reforming & (5) & $\mathrm{HHV}$ & Q \\
\hline Fletcher and Moen (1977) & Thermolysis & (3) & - & - \\
\hline Gokon et al. (2014) & Gasification & (5) & - & - \\
\hline Hathaway and Davidson, (2017) & Gasification & (6) & LHV & - \\
\hline Hathaway et al. (2016) & Thermochemical cycle & (5) or (6) & $\mathrm{HHV}$ & $Q$ \\
\hline Jarrett et al. (2016) & Thermochemical cycle & (5) or (6) & $\mathrm{HHV}$ & W \\
\hline Jin et al., 2018 & Reforming & (5) & - & - \\
\hline Koepf et al. (2016) & Thermochemical cycle & (5) or (6) & - & W \\
\hline Kong et al. (2016) & Reforming & (5) & $\mathrm{HHV}$ & - \\
\hline Kong et al. (2018) & Thermochemical cycle & (5) or (6) & $\mathrm{HHV}$ & Q \\
\hline Lapp et al. (2012) & Thermochemical cycle & (5) or (6) & $\mathrm{HHV}$ & $Q$ \\
\hline Li et al. (2021) & Thermochemical cycle & (5) or (6) & $\mathrm{HHV}$ & Q \\
\hline Marxer et al. (2017) & Thermochemical cycle & (5) or (6) & $\mathrm{HHV}$ & Q \\
\hline Müller et al. (2017) & Gasification & (6) & LHV & - \\
\hline Müller et al. (2018) & Gasification & (6) & LHV & - \\
\hline Muroyama et al. (2018) & Gasification & (6) & LHV & - \\
\hline Palumbo et al. (2015) & Reforming/Gasification & (6) & LHV & - \\
\hline Piatkowski et al. (2011) & Gasification & (6) & LHV & - \\
\hline Yuan et al. (2015) & Thermochemical cycle & (5) or (6) & $\mathrm{HHV}$ & W \\
\hline Z'Graggen et al. (2006) & Gasification & (5) & - & - \\
\hline Z'Graggen et al. (2008) & Gasification & (5) & - & - \\
\hline Zheng et al. (2015) & Reforming & (5) & $\mathrm{HHV}$ & - \\
\hline Zhu et al. (2016) & Membrane reactor & Other & $\mathrm{HHV}$ & - \\
\hline Zoller et al. (2019) & Thermochemical cycle & (5) or (6) & $\mathrm{HHV}$ & $Q$ \\
\hline
\end{tabular}

${ }^{a}$ The definitions given by Eqs 5, $\mathbf{6}$ are equivalent when the feedstock has a heating value of zero.

overlooked. However, efficiency is rarely defined explicitly as in Eq. 1 because $Q_{\text {waste }}$ is not usually a term that can be directly measured.

Before considering other efficiency definitions, it is important to first discuss the auxiliary work, as there is some variance in the treatment of this term in the literature. The auxiliary work $W_{\text {aux }}$ is not necessarily an energy consumption taking place within the reactor itself, however it is work that must be done in order for the reactor to operate, such as pumping or recycling sweep gas. It should therefore be included in the energy demand, $E_{\text {total }}$. However, in solar thermochemical fuel processes, the total energy is most often given as a purely thermal energy (see Table 1). Thus, $W_{\text {aux }}$ is substituted by an equivalent thermal energy input $Q_{\text {aux }}$, calculated using a heat-to-work efficiency,

$$
Q_{\text {aux }}=\frac{W_{\text {aux }}}{\eta_{\text {heat-to-work }}} \text {. }
$$

The total energy then includes the heat supplied to the reactor and the heat demand to perform the auxiliary work, $E_{\text {total }}=Q+Q_{\text {aux }}$, which in principal includes a power cycle within the system boundaries.

A range of values for the heat-to-work efficiency can be found in the literature, and here we are suggesting a value of $\eta_{\text {heat-to-work }}=0.4$ (Marxer et al., 2017). This conversion is academic in nature, while in practice grid electricity is typically used for auxiliary work or bottled gases in the case of sweep gas requirements. Even for a scaled up industrial plant it may be more economical and flexible to rely on grid electricity if it is available. Indeed, some studies have chosen to include the work directly in the total energy demand, as can be seen in Table $\mathbf{1}$. However, since the majority of researchers apply this conversion of work to an equivalent heat demand, we include it in the efficiency definitions described here.

We can now look at some common efficiency definitions seen in the literature and discuss the pros and cons of each. We first consider a definition based around the second law of thermodynamics,

$$
\eta=\frac{\sum_{i}^{\mathrm{prod}} \mathrm{n}_{\mathrm{i}} G_{\mathrm{i}}-\sum_{i}^{\mathrm{feed}} \mathrm{n}_{\mathrm{i}} G_{\mathrm{i}}}{E_{\text {total }}}
$$

where $\sum_{i}^{\text {prod }} \mathrm{n}_{\mathrm{i}} G_{\mathrm{i}}$ is the total Gibbs free energy of the products, and $\sum_{i}^{\text {feed }} \mathrm{n}_{\mathrm{i}} G_{\mathrm{i}}$ is the total Gibbs free energy of the feedstock. Thus, the numerator represents the change in Gibbs free energy of the process, which is equivalent to the theoretical maximum work 
that can potentially be performed by the reverse process. This definition was often used in the pioneering research of Fletcher on solar-driven processes (Noring and Fletcher 1982). Fletcher also derived a theoretical upper bound for this efficiency, given by:

$$
\eta_{\max }=\left(1-\frac{\sigma T_{\mathrm{H}}^{4}}{I C}\right)\left(1-\frac{T_{\mathrm{L}}}{T_{\mathrm{H}}}\right),
$$

where $I$ is the DNI, $C$ is the solar concentration ratio, $T_{\mathrm{H}}$ and $T_{\mathrm{L}}$ are the temperatures of the upper and lower thermal reservoirs of an equivalent heat engine, and $\sigma$ is the Stefan-Boltzmann constant (Fletcher and Moen 1977). This upper bound results from multiplying of the maximum solar absorption efficiency of a perfectly-insulated blackbody cavity-receiver (taking into account only radiation losses), and the Carnot efficiency for the maximum conversion of heat to work. One issue with the efficiency according to Eq. 3 is that it relates to the fuel's potential to perform work, but the energy available in a fuel is usually quantified in terms of its heating value, which leads to an alternative efficiency definition, given by:

$$
\eta=\frac{\sum_{i}^{\mathrm{prod}} n_{i} \mathrm{HHV}_{\mathrm{i}}-\sum_{i}^{\mathrm{feed}} n_{i} \mathrm{HHV}_{\mathrm{i}}}{E_{\text {total }}}
$$

where HHV denotes the higher heating value and the numerator denotes the change in the heating value between the products and the feedstock. Note that lower heating value (LHV) can also be used, as discussed later. The numerator in this case is equivalent to the enthalpy change of the reaction. This efficiency definition has a direct relation to the fuel properties and has been applied in publications on both natural gas reforming and biomass gasification (Jin et al., 2018; Z'Graggen and Steinfeld 2008).

One issue with Eq. 5 is that it can take negative values for some processes. Take for example solar biomass gasification in a hybrid reactor that can switch between solar thermal operation and auto-thermal operation by supplying some oxygen when off Sun (Muroyama et al. (2018), Boujjat et al., 2020). When such a hybrid system is in auto-thermal operation, the heating value of the feedstock would be decreased by the process and the efficiency according to Eq. 5 would be negative. Another interesting example is solar fast pyrolysis of biomass (Zeng, et al., 2017; Bashir et al., 2017), in which the biomass is thermally decomposed in the absence of an oxidizing agent such as steam or oxygen. Depending on the feedstock, this process can become net exothermic (Di Blasi et al., 2017), but a heat source is still required for the rapid heating of the feedstock and starting the decomposition. In this case the efficiency according to Eq. 5 would become negative even during solar operation.

To avoid the possibility of negative efficiencies we can consider the heating value of the feedstock as an energy input to the system, and include it in the denominator, $E_{\text {total }}$. For $\mathrm{H}_{2} \mathrm{O}$ and $\mathrm{CO}_{2}$ splitting cycles, the corresponding heating values are zero. But this is not the case for example for the gasification of biomass or for the reforming of hydrocarbons (Piatkowski et al., 2011; Muroyama et al., 2018; Müller et al., 2017). The efficiency is then defined as,

$$
\eta=\frac{\sum_{i}^{\text {prod }} n_{i} \mathrm{HHV}_{\mathrm{i}}}{E_{\text {total }}}
$$

where the total energy now includes the solar heat supplied to the reactor, the equivalent heat for auxiliary work, and the heating value in the feedstock, $E_{\text {total }}=Q+Q_{\text {aux }}+\sum_{i}^{\text {feed }} n_{\mathrm{i}} H H V_{\mathrm{i}}$. Eq. 6 is equivalent to Eq. 5 if the feedstock itself has no heating value (e.g., $\mathrm{H}_{2} \mathrm{O}$ or $\mathrm{CO}_{2}$ ). This definition is equivalent to Eq. 1, in that it tracks the fraction of waste heat released in the process as the difference between the denominator and numerator. The heat losses can be radiation, convection, and conduction losses, losses in sensible heat from the products, and waste heat from the generation of $W_{\text {aux }}$ (see Eq. 2). Thus, Eq. 6 can be generally applied to any solar thermochemical fuel production process described in Figure 1, will always take a value between 0 and 1, and reflects the fraction of the energy supplied which is available in the fuel.

An interesting point to note is that Eqs 5, 6 are heat-to-heat efficiencies and can have a larger value than the heat-to-work efficiency given by Eqs 3, 4. They are bounded by only the first bracketed term of Eq. 4, which is the maximum absorption efficiency. Thus, while the second law of thermodynamics places a limit on the efficiency according to Eq. 3, only the first law of thermodynamics places a limit on the efficiency according to Eqs 5, 6. This fact is very frequently overlooked, where many studies use a heat-to-heat efficiency definition and state Eq. 3 as an upper bound.

Another point worth noting is that some cases have a number of options for what is included as part of the products in the numerator of the efficiency definition given in Eq. 6. This can require some additional thought, and as a general rule we suggest only the products that are considered to be the produced fuel should be included, while the heating value of unusable byproducts or unreacted feed that cannot be recycled should be neglected. Take for example the thermal cracking of methane for the production of hydrogen (Maag et al., 2009; Rodat et al., 2011),

$$
\mathrm{CH}_{4} \rightarrow \mathrm{C}(\mathrm{s})+2 \mathrm{H}_{2},
$$

which forms gaseous hydrogen and solid phase carbon as a byproduct. If only the produced hydrogen is intended to be used as a fuel, and the carbon is sequestered, then the heating value of the carbon byproduct should not be included in the numerator. Similarly, if there is unconverted methane which cannot be recycled or used in the final fuel it should also be omitted from the numerator giving an efficiency,

$$
\eta=\frac{n_{\mathrm{H}_{2}} \mathrm{HHV}_{\mathrm{H}_{2}}}{Q+\text { Qaux }+n_{\mathrm{CH}_{4}} \mathrm{HHV}_{\mathrm{CH}_{4}}} .
$$

The heating value of the byproduct and the heating value of the unconverted feedstock would then be considered part of the waste heat in the efficiency according to Eq. 1, which effectively closes the energy balance.

When choosing the efficiency, we should also consider the prevalence of each definition in the literature, as past work does 
set some precedent. A selection of publications with explicitly defined efficiencies are shown in Table 1. We distinguish the equations quite generally by whether the use change in Gibbs free energy as in Eq. 3, the change in heating value or enthalpy as in Eq. 5, or include the heating value of the feed in the denominator as in Eq. 6.

From Table 1, it can be seen that both Eqs 5, 6 are frequently applied in gasification and reforming processes. Eq. 6 is the most general formulae, in that it can be applied to a reactor or an entire process chain, as well as solar and nonsolar processes. Consider for example a conventional oil refinery where some of the feed is combusted to provide the heat required for the plant. In this case we cannot apply Eq. 3 or Eq. 5 as they will both give a negative efficiency, but Eq. 6 would be suitable. Similarly, if we consider a complete solar fuel production process consisting of the endothermic solar gasification of biomass followed by exothermic FischerTropsch synthesis and subsequent refining of the hydrocarbons, the end product can have less heating value than the original biomass. Again we cannot apply Eq. 3 or Eq. 5 to this complete process as they would give negative values. Therefore, as the most general formula which is already commonly applied, Eq. 6 is the recommended efficiency definition for future studies.

It is often the case that authors want to gauge the solar energy demand per unit of fuel produced, as the solar concentrating infrastructure can make up for a significant part of the capital investment. For gasification and reforming processes, the efficiency defined by Eq. 6 does not provide this directly. To provide this information one can further define dimensionless energy factors (Jarret et al., 2016, Li et al., 2021),

$$
F_{i}=\frac{Q_{\mathrm{i}}}{\sum_{i}^{\text {prod }} n_{i} \mathrm{HHV}_{\mathrm{i}}}
$$

which gives a specific energy demand relative to the fuel's heating value. The efficiency is then related to the energy factors by $\eta=$ $\frac{1}{\sum_{i} F_{i}}$. The solar energy factor would then be $F_{\text {solar }}=\frac{Q_{\text {solar }}}{\sum_{i}^{\text {products }} n_{i} \mathrm{HHV}_{\mathrm{i}}}$. Similarly one can give a more detailed breakdown of the energy demands by giving factors for subsystems such as the auxiliary work $F_{\text {aux }}=\frac{W_{\text {aux }}}{\sum_{i}^{\text {prod }} n_{i} \mathrm{HHV}_{\mathrm{i}}}$, or the heating value of the feedstock $F_{\text {feed }}=\frac{\sum_{i}^{\text {feed }} n_{i} \mathrm{HHV}_{\mathrm{i}}}{\sum_{i}^{\text {prod }}{ }_{n_{i} \mathrm{HHV}_{\mathrm{i}}}}$. In this way, a more complete breakdown of the energy balance can be reported together with the efficiency.

Note that other efficiency definitions are found in the literature, some of which are difficult to interpret and should be avoided. For example, subtracting the auxiliary work term from the numerator rather than including it in the denominator (Zhu et al., 2016),

$$
\eta=\frac{\sum_{i}^{\text {feed }} n_{\mathrm{i}} \mathrm{HHV}_{\mathrm{i}}-W_{\mathrm{aux}}}{Q+\sum_{i}^{\text {prod }} n_{i} \mathrm{HHV}_{\mathrm{i}}}
$$

as this leads to an equation which can easily have negative values. Another variation encountered is the inclusion of the conversion extent of the feedstock $X_{\text {feed }}$ in the denominator of the efficiency definition (Chuayboon et al., 2019)

$$
\eta=\frac{\sum_{i}^{\text {prod }} n_{i} \mathrm{HHV}_{\mathrm{i}}}{X_{\text {feed }} n_{\text {feed }} \mathrm{HHV}_{\text {feed }}+Q+Q_{\text {aux }}} .
$$

which mixes up the benchmarks for mass balance with that of the energy balance.

Higher heating value (HHV) vs. lower heating value (LHV)Some sources use LHV instead of HHV (Table 1). If there is hydrogen or hydrocarbons in the products this will lead to lower efficiency values. The use of $\mathrm{HHV}$ is recommended because it offers a strict upper-bound for the useful thermal energy that can be extracted from the fuel in all applications.

\section{CONVERSION EXTENT, SELECTIVITY, AND YIELD}

These performance indicators are based on the mass balance and are used to keep track of the chemical reactions taking place, and they are, along with energy efficiency, the most important metrics for assessing the performance of chemical reactors. The conversion extent monitors how much of the feedstock supplied undergoes a chemical change within the reactor, while the selectivity gauges the extent of unwanted side reactions. The yield is the product of conversion and selectivity, and it gives the amount of the desired product formed relative to the stoichiometric maximum product formation, and thus provides information about the purity of the fuel produced. This means that reporting conversion extent and selectivity (or yield) gives the information needed to benchmark the system, while only reporting one of them leaves ambiguity about the other two. Together, these mass balance metrics have very useful implications for reactor design, including relating the reactor free volume and flow rates to production rates, which in turn can be used to rule out processes as unfeasible for large scale industrial production (Lange 2016). For example, a process can exhibit total (100\%) selectivity for the conversion of $\mathrm{CO}_{2}$ to $\mathrm{CO}$, but if its conversion extent is low, it will lead to a fuel of little practical application because of the high dilution in unreacted $\mathrm{CO}_{2}$. Although these metrics can be considered the nuts and bolts of chemical engineering research, they are often omitted in solar reactor studies.

We first define these indicators for a generic chemical reactor and then give examples for the solar fuel production processes discussed. We follow the definitions formulated in the seminal chemical reactor engineering text book by Levenspiel (2001). The conversion extent is generally formulated in terms of a limiting reactant. The limiting reactant is the reactant fed to the reactor which can be completely consumed according to the chemical reaction stoichiometry and input flow rates. For a trivial chemical process, such as

$$
\mathrm{A} \rightarrow \mathrm{B}
$$

with only one feedstock, species $A$ is the limiting reactant and $B$ is the desired product. A chemical reactor for this processes is illustrated in Figure 3. 


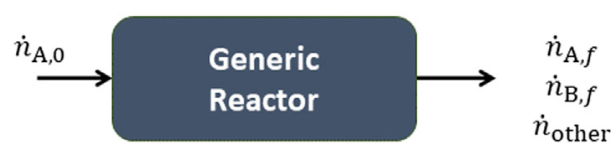

FIGURE 3 | A continuous-flow thermochemical reactor with an input molar feed rate of $\dot{\boldsymbol{n}}_{\mathbf{A}, 0}$, and a product stream with outflows $\dot{\boldsymbol{n}}_{\mathbf{A}, \boldsymbol{f}}$,

$\dot{\boldsymbol{n}}_{\mathrm{B}, \boldsymbol{f}}$ and. $\dot{\boldsymbol{n}}_{\text {other }}$

The conversion extent for this process can be defined as the relative change in the number of moles of the limiting reactant,

$$
X_{\mathrm{A}}=1-\frac{\dot{n}_{\mathrm{A}, f}}{\dot{n}_{\mathrm{A}, 0}} .
$$

where the subscript 0 indicates an input flow rate and the subscript $f$ indicates the final flow rate at the exit of the reactor. For a batch reactor we can use the same formulae but with the number of initial and final moles, instead of molar flow rates. The importance of the conversion extent as a performance indicator is highlighted in classical text's where the performance equation of a chemical reactor gives the relation between the free volume, species flow rates and the conversion extent (Levenspiel 2001). For example, if we can only achieve a low conversion extent of say $10 \%$, and we assume perfect selectivity, then we must have a feedstock flow rate which is 10 times higher than the desired production rate, and a large volume reactor to accommodate the flow, which has obvious implications for the cost and practical feasibility of a process.

As well as the desired reaction there can also be undesired reactions, for example,

$$
\mathrm{A}+\mathrm{B} \rightarrow \mathrm{C},
$$

where $A$ is the reactant, $B$ is the desired product, and $C$ is an undesired product. The selectivity of the reactor towards species $B$ is defined as the production rate of the desired product $B$ relative to consumption rate of the feedstock $A$,

$$
S_{\mathrm{B}}=\frac{\dot{n}_{\mathrm{B}, f}}{\dot{n}_{\mathrm{A}, 0}-\dot{n}_{\mathrm{A}, f}} .
$$

If there are no side reactions we would have $\dot{n}_{\mathrm{B}, f}=\dot{n}_{\mathrm{A}, 0}-\dot{n}_{\mathrm{A}, f}$, resulting in a selectivity of 1 . The yield is the amount of desired product formed relative to the maximum amount of desired product that can be formed, i.e., it is the product of conversion extent and selectivity,

$$
Y_{\mathrm{B}}=X_{\mathrm{A}} S_{\mathrm{B}}=\frac{\dot{n}_{\mathrm{B}, f}}{\dot{n}_{\mathrm{A}, 0}} .
$$

Note then that reporting conversion extent, selectivity, and feed rates can offer a complete description of the chemical transformation in the reactor. However, if the system does not have an ideal selectivity of $S=1$, it is also recommended to report the yield too.

Another point worth noting is that the selectivity and yield need to be adjusted by the relative stoichiometry of the product to the limiting reactant. For example, for the reaction $A \rightarrow 2 B$, the selectivity would be given by $S_{\mathrm{B}}=\frac{1}{2} \frac{\dot{n}_{\mathrm{B}, f}}{\dot{n}_{\mathrm{A}, 0}-\dot{n}_{\mathrm{A}, f}}$, where the factor of one half accounts for the 2 moles of $B$ formed for every 1 mole of $A$ reacted.

When reporting on the mass balance for reactor demonstrations it is recommend to report.

a) The feedstock molar flow rates (or mass flow rates for biomass).

b) The conversion extent of the feedstock in terms of the limiting reactant.

c) The selectivity towards the desired product, and the yield.

In trivial cases where the selectivity can be assumed to have a value of 1 , then the conversion extent and yield will be equal. In such cases this should be clearly stated in the results.

\section{STABILITY}

The reactor's performance stability can be reported using the same mass and energy balance performance indicators described above, by giving their values as a function of time (or cycle \# for cyclic processes). In other words, the efficiency $\eta$ given by Eq. 6, conversion extent $X_{i}$ given by Eq. 13, the selectivity $S_{i}$ given by Eq. 15, and the yield given by Eq. 16, should all be monitored over time to gauge the stability of the performance. Other stability issues such as degradation or complete failure of components are much more difficult to report in a consistent way, as there are no scalable measurements of such faults that can be broadly applied. We therefore restrict our recommendations to recording the performance indicators over time.

\section{EXAMPLES OF THE PERFORMANCE INDICATORS}

Here we outline the performance indicators for some example processes that have been investigated in the literature, namely: solar reforming, thermochemical redox cycles and solar biomass gasification.

Solar methane reforming-Methane can be converted to syngas by reacting it with steam at high temperatures via the endothermic reforming reaction,

$$
\mathrm{CH}_{4}+\mathrm{H}_{2} \mathrm{O} \rightarrow \mathrm{CO}+3 \mathrm{H}_{2},
$$

The heat for this reaction can be supplied by concentrated solar energy (Agrafiotis et al., 2014). This can be performed with a continuous flow reactor as illustrated in Figure 4. The process can also have numerous side reactions such as the reverse water-gas shift,

$$
\mathrm{CO}+\mathrm{H}_{2} \mathrm{O} \rightarrow \mathrm{CO}_{2}+\mathrm{H}_{2}
$$

For this process we consider the syngas components $\mathrm{CO}$ and $\mathrm{H}_{2}$ to be the produced fuel and the unreacted methane to be lost, so that the efficiency is given as (Eq. 6); 


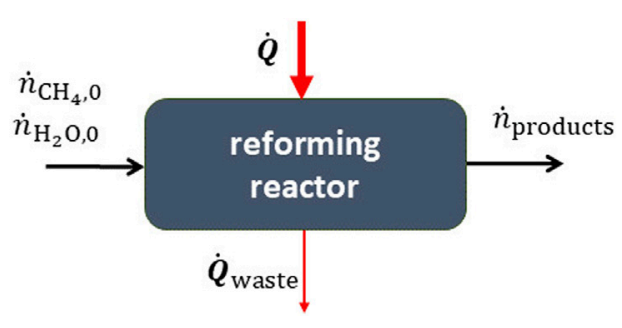

FIGURE 4 | A thermochemical reactor for the steam reforming of methane. The heat input is supplied by concentrated solar energy.

$$
\eta=\frac{\dot{n}_{\mathrm{H}_{2}} \mathrm{HHV}_{\mathrm{H}_{2}}+\dot{n}_{\mathrm{CO}} \mathrm{HHV}_{\mathrm{CO}}}{\dot{n}_{\mathrm{CH}_{4}, 0} \mathrm{HHV}_{\mathrm{CH}_{4}}+\dot{Q}} .
$$

where the sum in the numerator is over the species flow rates in the products times their HHVs. To avoid coking, steam is used in excess with $\dot{n}_{\mathrm{H}_{2} \mathrm{O}}>\dot{n}_{\mathrm{CH}_{4}}$ and methane as the limiting reactant, with conversion extent given by,

$$
X_{\mathrm{CH}_{4}}=1-\frac{\dot{n}_{\mathrm{CH}_{4}, f}}{\dot{n}_{\mathrm{CH}_{4}, 0}} .
$$

The presence of side reactions means that we should also consider the selectivity towards the syngas products $\mathrm{CO}$ and $\mathrm{H}_{2}$, given by:

$$
\mathrm{S}_{\mathrm{CO}}=\frac{\dot{n}_{\mathrm{CO}, f}}{\dot{n}_{\mathrm{CH}_{4}, 0}-\dot{n}_{\mathrm{CH}_{4}, f}} \text { and } \mathrm{S}_{\mathrm{H}_{2}}=\frac{\dot{n}_{\mathrm{H}_{2}, f}}{3\left(\dot{n}_{\mathrm{CH}_{4}, 0}-\dot{n}_{\mathrm{CH}_{4}, f}\right)} \text {. }
$$

Solid phase carbon is an unwanted product which can form due to the Boudouard reaction or methane cracking. If present, this can be quantified using the carbon yield (Bulfin et al., 2021),

$$
\mathrm{Y}_{\mathrm{C}}=\frac{\dot{n}_{\mathrm{C}}}{\dot{n}_{\mathrm{CH}_{4}, 0}},
$$

but ideally it should be zero. Note the formulae given can be rearranged to be in terms of feed rate, and mole fractions in the product stream, as required by the type of measurements taken in the experiment. However, it should be checked that definitions used are equivalent to the standard versions given here.

Thermochemical redox cycles-Two-step metal oxide redox cycles can be used to split $\mathrm{H}_{2} \mathrm{O}$ and $\mathrm{CO}_{2}$, producing $\mathrm{H}_{2}$ and CO (Romero and Steinfeld, 2012; Bulfin et al., 2017). A metal oxide first undergoes reduction at high temperature and low oxygen partial pressures,

$$
M O_{\text {ox }} \rightarrow M O_{\text {red }}+\frac{\delta}{2} \mathrm{O}_{2}
$$

and is then reacted at lower temperature with $\mathrm{H}_{2} \mathrm{O}$ or $\mathrm{CO}_{2}$ to form $\mathrm{H}_{2}$ and $\mathrm{CO}$,

$$
\begin{aligned}
& M O_{\text {red }}+\mathrm{CO}_{2} \rightarrow M O_{\text {ox }}+\mathrm{CO} \\
& M O_{\text {red }}+\mathrm{H}_{2} \mathrm{O} \rightarrow M O_{\text {ox }}+\mathrm{H}_{2}
\end{aligned}
$$

Both redox reactions can be performed in the same fixed-bed reactor but at different times in a cyclic sequential mode
(Hathaway et al., 2016; Haeussler et al., 2020; Marxer et al., 2017). Alternatively, it could be operated continuously using a particle transport reactor (Ermanoski et al., 2013; Singh et al., 2017; Welte et al.,2016). The process is illustrated in Figure 5, where it is important to note that reduction and oxidation are either taking place at different times or in separate reaction chambers.

In the fixed bed case, the system parameters; temperature, pressure, input power, conversion extent, auxiliary work etc., are varying in time. Therefore, integrals are taken over an entire cycle to obtain the desired performance parameters. For $\mathrm{CO}_{2}$-splitting, we define the efficiency as,

$$
\eta=\frac{\mathrm{HHV}_{\mathrm{CO}} \int_{0}^{t_{\text {cycle }}} \dot{n}_{\mathrm{CO}}(t) \mathrm{d} t}{\int_{0}^{t_{\text {cycle }}} \dot{\mathrm{Q}}(\mathrm{t})+\dot{Q}_{\mathrm{aux}}(t) \mathrm{d} t} .
$$

Auxiliary work may include vacuum pumping during reduction and the production of inert sweep gas. This definition is the same for water splitting, where $\mathrm{CO}$ is replaced by $\mathrm{H}_{2}$. In this case the conversion extent is given by:

$$
X_{\mathrm{CO}_{2}}=1-\frac{\int_{0}^{t_{\text {cycle }}} \dot{n}_{\mathrm{CO}_{2}, f} \mathrm{~d} t}{\int_{0}^{t_{\text {cycle }}} \dot{n}_{\mathrm{CO}_{2}, 0} \mathrm{~d} t} .
$$

The selectivity towards $\mathrm{CO}$ is given by:

$$
\mathrm{S}_{\mathrm{CO}}=\frac{\int_{0}^{t_{\text {cycle }}} \dot{n}_{\mathrm{CO}, f} \mathrm{~d} t}{\int_{0}^{t_{\mathrm{cycle}}} \dot{n}_{\mathrm{CO}_{2}, 0}-\dot{n}_{\mathrm{CO}_{2}, f} \mathrm{~d} t} .
$$

The yield is given by $Y_{\mathrm{CO}}=X_{\mathrm{CO}_{2}} S_{\mathrm{CO}}$.

The literature on thermochemical redox cycles is perhaps the most problematic in terms of reporting standards due to the more complex nature of the cyclic process. There are a few articles in the literature which address all the performance indicators described here, with the work of Marxer et al. a notable example (Marxer et al., 2017). However, many studies omit the conversion extent, selectivity and yield as defined here, and instead only report the moles of $\mathrm{H}_{2}$ or $\mathrm{CO}$ produced per gram of the cycled redox material as the yield (Agrafiotis et al., 2005; Hathaway et al., 2016; Haeussler et al., 2020). Reporting the mass balance using the performance indicators defined here together with the efficiency will offer a more complete picture of the performance. As additional

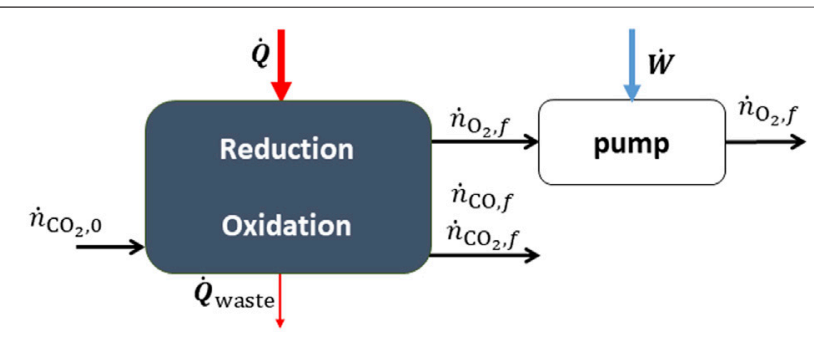

FIGURE 5|A thermochemical reactor for the redox splitting of $\mathrm{CO}_{2}$. The heat input is supplied by concentrated solar energy. 


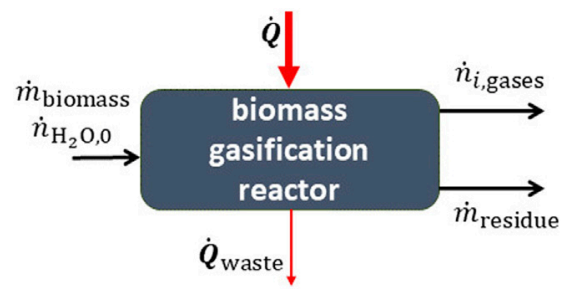

FIGURE 6 | A reactor for the gasification of biomass. The hightemperature heat input is supplied by concentrated solar energy.

information the moles of fuel per mole of redox material can also be reported, but to avoid confusion this parameter should not be referred to as the yield.

An interesting example that emphasizes the importance of reporting both energy and mass balance performance indicators is that of isothermal redox cycles. In this case both redox steps are conducted at the same temperature by performing a pressure swing. Studies have focused on the energy efficiency (Ermanoski et al., 2014) and experimental demonstrations of the process (Muhich et al., 2013; Hathaway et al., 2016; Hoskins et al., 2019). The conversion extent in the demonstrations are typically not reported, but at the operating conditions considered it is known to be thermodynamically limited to low values on the order of $X \approx 0.01$ (Ermanoski et al., 2014; Bulfin et al., 2016). The feedstock flow rate of $\mathrm{H}_{2} \mathrm{O}$ or $\mathrm{CO}_{2}$ required for a given output is inversely proportional to the conversion extent, with such low values resulting in considerable practical limitations for scalingup the process. Low conversion extents lead to large feedstock flow rates, which in turn lead to larger reactors with increased capital cost and impractical design constraints. For this reason, classical chemical reactor engineering texts put a large emphasis on the conversion extent as a performance indicator (Levenspiel 2001).

Solar biomass gasification-Biomass, coal, or carbonaceous materials can be reacted with steam at high temperatures to produce syngas, as illustrated in Figure 6 (Piatkowski et al., 2011). Since biomass does not have a simple chemical composition, the mass balance is more complex than the previous examples. Proximate and ultimate analysis are required to determine the chemical breakdown of the biomass (Müller et al., 2018; Muroyama et al., 2018).

Biomass gasification is a combination of many independent reactions with the net reaction summarized by the formula,

$$
\begin{aligned}
& \mathrm{C}_{\mathrm{n}} \mathrm{H}_{\mathrm{m}} \mathrm{O}_{\mathrm{k}}+\mathrm{yH}_{2} \mathrm{O} \rightarrow x_{1} \mathrm{CO}+x_{2} \mathrm{CO}_{2}+x_{3} \mathrm{H}_{2}+x_{4} \mathrm{CH}_{4} \\
& \quad+\text { other gases + residue, }
\end{aligned}
$$

where $\mathrm{C}_{n} \mathrm{H}_{m} \mathrm{O}_{k}$ represents biomass. The biomass generally contains sulphur and nitrogen impurities on the order of $1 \%$ by mass. The efficiency can be expressed as;

$$
\eta=\frac{\sum_{i}^{\text {prod }} \dot{m}_{i} \mathrm{HHV}_{i}}{\dot{Q}+\dot{m}_{\text {biomass }} \mathrm{HHV}_{\text {biomass }}} .
$$

where we only sum the heating value of the gasified products, as the residue is an ash like byproduct and not a fuel. Note that the HHV are per unit mass and not per mole as in other formulae, which is due to the fact that the feed does not have a well-defined stoichiometric chemical formula. In this case an upgrade factor is also often reported, defined by the relative change in the heating value between the products and feedstock,

$$
U=\frac{\sum_{i}^{\text {prod }} \dot{m}_{\mathrm{i}} \mathrm{HHV}_{\mathrm{i}}}{\dot{m}_{\text {biomass }} \mathrm{HHV}_{\text {biomass }}} .
$$

The value of $U$ depends on the type of feedstock and the syngas yield. This value can offer non-redundant information on the energy balance when reported together with the efficiency. For carbonaceous materials, the conversion extent is usually defined in terms of the carbon conversion extent (Müller et al., 2018),

$$
X_{\mathrm{C}}=1-\frac{\dot{m}_{\mathrm{C}-\text { residue }}}{\dot{m}_{\mathrm{C}, 0}},
$$

where $\dot{m}_{\mathrm{C}, 0}$ is the mass flow rate of carbon in the biomass feed (determined by ultimate analysis), and $\dot{m}_{\mathrm{C}-\text { residue }}$ is the mass of carbon in the residue (the unreacted carbon), which can be made up of tar and ash. The carbon to syngas yield can be expressed using molar flow rates of carbon containing species in the gas stream,

$$
Y_{\text {syngas }}=\frac{\sum_{i}^{\text {gases }} v_{i, C} \dot{n}_{\mathrm{i}, \mathrm{gas}}}{\dot{n}_{\mathrm{C}, 0}}=\frac{\dot{n}_{\mathrm{CO}}+\dot{n}_{\mathrm{CO}_{2}}+\dot{n}_{\mathrm{CH}_{4}}+2 \dot{n}_{\mathrm{C}_{2} \mathrm{H}_{6}}+\ldots}{\dot{n}_{\mathrm{C}, 0}} .
$$

where $v_{i, C}$ is the stoicheometric number of carbon in the gas species. Often this sum is only performed for $\mathrm{CO}, \mathrm{CO}_{2}$, and $\mathrm{CH}_{4}$, which differentiates it from the conversion extent defined above. Given the large number of reactions present there are a number of different selectivity's which may be of interest. For downstream gas-to-liquid processes, $\mathrm{CO}$ may be favored over $\mathrm{CO}_{2}$ and $\mathrm{CH}_{4}$, in which case the selectivity towards $\mathrm{CO}$ can be defined as,

$$
S_{\mathrm{CO}}=\frac{\dot{n}_{\mathrm{CO}}}{\sum_{i}^{\text {gases }} v_{i, \mathrm{C}} \dot{n}_{\mathrm{i}, \mathrm{gas}}}=\frac{\dot{n}_{\mathrm{CO}}}{\dot{n}_{\mathrm{CO}}+\dot{n}_{\mathrm{CO}_{2}}+\dot{n}_{\mathrm{CH}_{4}}} .
$$

\section{SUMMARY OF REPORTING PROTOCOLS}

The dimensioned parameters required to described the reactor system are:

1) The reactor volume and free volume.

2) Mass loading of cycled redox material or catalyst.

3) The operating conditions of the reactor (e.g., temperature, pressure, etc.).

4) The molar/mass flow rates of feedstock into the reactor.

5) The total heat supply to the reactor, $Q$ (e.g., solar heat, etc.).

6) Auxiliary work demands, $W_{\text {aux }}$, (e.g., pumping work, inert gas production, etc.). 
TABLE 2 | The performance indicatoars for the example solar fuel processes discussed in this work.

\begin{tabular}{|c|c|c|c|}
\hline Reactor type & Efficiency $\eta$ & Conversion extent $\boldsymbol{X}_{\boldsymbol{i}}$ & $\begin{array}{c}\text { Selectivity (or Yield) } \\
\text { S (or } Y \text { ) }\end{array}$ \\
\hline \multirow[t]{2}{*}{ Thermochemical redox $\mathrm{CO}_{2}$ splitting } & $\mathrm{HHV}_{\mathrm{CO}} \int_{0}^{t_{\mathrm{cycle}}} \dot{n}_{\mathrm{CO}}(t) \mathrm{d} t$ & \multirow{2}{*}{$1-\frac{\int_{0}^{t_{\text {Cycle }}} \dot{n}_{\mathrm{CO}_{2}, f} \mathrm{~d} t}{\int_{0}^{t_{\mathrm{Cycle}}} \dot{n}_{\mathrm{CO}_{2}, \mathrm{O}} \mathrm{d} t}$} & $\int_{0}^{t_{\mathrm{Cycle}}} \dot{n}_{\mathrm{CO}, f} \mathrm{~d} t$ \\
\hline & $\int_{0}^{t} t_{\text {cycle }} \dot{Q}(\mathrm{t})+\dot{Q}_{\mathrm{aux}}(t) \mathrm{d} t$ & & $\int_{0}^{t_{\mathrm{cycle}}} \dot{n}_{\mathrm{CO}_{2}, 0}-\dot{n}_{\mathrm{CO}_{2}, f} \mathrm{~d} t$ \\
\hline Solar methane reforming & $\frac{\sum_{i}^{\text {products }} \dot{n}_{\mathrm{i}} \mathrm{HHV}_{\mathrm{i}}}{\dot{\mathrm{Q}}+\dot{n}_{\mathrm{CH}_{4}, \mathrm{O}} \mathrm{HHV}_{\mathrm{CH}_{4}}}$ & $1-\frac{\dot{n}_{\mathrm{CH}_{4}, f}}{\dot{n}_{\mathrm{CH}_{4}, \mathrm{O}}}$ & $\frac{\dot{n}_{\mathrm{CO}, f}}{\mathrm{CH}_{4}, 0-\dot{n}_{\mathrm{CH}_{4}, f}}$ \\
\hline Biomass gasification & $\frac{\sum_{i}^{\text {prod }} \dot{m}_{\mathrm{i}} \mathrm{HHV} \mathrm{V}_{\mathrm{i}}}{\dot{\mathrm{Q}}+\dot{m}_{\text {biomass }} \mathrm{HHV}_{\text {biomass }}}$ & $1-\frac{\dot{m}_{\mathrm{C}-\text { residue }}}{\dot{m}_{\mathrm{C}, 0}}$ & $Y_{\text {syngas }}=\frac{\sum_{i}^{\text {gases }} v_{i, C} \dot{n}_{\text {, gas }}}{\dot{n}_{\mathrm{C}, 0}}$ \\
\hline Generic $\mathbf{A} \rightarrow \mathbf{B}$ & $\frac{\dot{n}_{\mathrm{B}} H H V_{\mathrm{B}}}{\dot{Q}+\dot{Q}_{\mathrm{aux}}+\dot{n}_{\mathrm{A}} \mathrm{HHV} \mathrm{V}_{\mathrm{A}}}$ & $1-\frac{\dot{n}_{A, f}}{\dot{n}_{\mathrm{A}, 0}}$ & $\frac{i_{B, f}}{0-\dot{n}_{A, f}}$ \\
\hline
\end{tabular}

This information should enable the study to be reproduced or modelled by other researchers. The energy and mass balance performance indicators outlined in the previous sections allows for the system to be benchmarked. These are:

1) The energy efficiency: $\quad \eta=\frac{\sum_{i}^{\text {prod }} n_{i} \mathrm{HHV}_{\mathrm{i}}}{Q+Q_{\text {aux }}+\sum_{i}^{\text {feed }} n_{i} \mathrm{HHV}_{\mathrm{i}}}$. For solar-upgrading processes such as gasification and reforming, report additionally the upgrade factor: $U=$ $\frac{\sum_{i}^{\text {prod }} n_{i} \mathrm{HHV}_{\mathrm{i}}}{\sum_{i}^{\text {feed }} n_{i} \mathrm{HHV}_{\mathrm{i}}}$.

2) The conversion extent: $X_{\mathrm{A}}=1-\frac{\dot{n}_{\mathrm{A}, f}}{\dot{n}_{\mathrm{A}, 0}}$.

3) The selectivity towards the desired product: $S_{\mathrm{B}}=\frac{\dot{n}_{\mathrm{B}, f}}{\dot{n}_{\mathrm{A}, 0}-\dot{n}_{\mathrm{A}, f}}$, or the yield of the desired product: $Y_{\mathrm{B}}=\frac{\dot{n}_{\mathrm{B}, f}}{\dot{n}_{\mathrm{A}, 0}}$, for the case that the selectivity is not reported.

4) Performance stability, i.e., report the above indicators over time.

The example definitions given for these performance indicators are summarized in Table 2.

Conversion extent, product selectivity, and energy efficiency, combined with mass flow rates offer a complete description of the reactor performance, while the performance over time can be used to gauge stability. For cyclic processes, the benchmarks should use integrals of the performance indicators over an entire cycle as outlined here. Similarly, for continuous processes, the benchmarks should use steady-state or integrals over time of the heat and mass flow rates when calculating the performance indicators.

\section{REFERENCES}

Abanades, S., Rodat, S., and Boujjat, H. (2021). Solar Thermochemical Green Fuels Production: A Review of Biomass Pyro-Gasification, Solar Reactor Concepts and Modelling Methods. Energies 14 (5), 1494. doi:10.3390/en14051494

Agrafiotis, C., Roeb, M., Konstandopoulos, A. G., Nalbandian, L., Zaspalis, V. T., Sattler, C., et al. (2005). Solar Water Splitting for Hydrogen Production with Monolithic Reactors. Solar Energy 79 (4), 409-421. doi:10.1016/ j.solener.2005.02.026

\section{DATA AVAILABILITY STATEMENT}

The original contributions presented in the study are included in the article/Supplementary Material, further inquiries can be directed to the corresponding author.

\section{AUTHOR CONTRIBUTIONS}

BB wrote the manuscript and assisted in the planning of the study. MM performed a review of the solar fuel production literature and assisted in writing the article. AS assisted in the planning of the study and in the writing of the article.

\section{FUNDING}

This research work was funded by the European Union's Horizon 2020 Research Infrastructure Programme (Project SFERAIII-Grant Nr. 823802) and by the Swiss Federal Office of Energy (Project SOLIFUEL-Grant Nr. SI/501213-01).

\section{ACKNOWLEDGMENTS}

We would like to thank Martin Roeb, Valéry Vuillerme, Silvane Rodat, Ricardo Sanchez and other members of the SFERA III consortium who offered feedback on the formulation of standardized reporting protocols for solar fuel processes and reactors.

Agrafiotis, C., Roeb, M., and Sattler, C. (2015). A Review on Solar thermal Syngas Production via Redox Pair-Based Water/carbon Dioxide Splitting Thermochemical Cycles. Renew. Sust. Energ. Rev. 42, 254-285. doi:10.1016/ j.rser.2014.09.039

Agrafiotis, C., von Storch, H., Roeb, M., and Sattler, C. (2014). Solar thermal Reforming of Methane Feedstocks for Hydrogen and Syngas Production-A Review. Renew. Sust. Energ. Rev. 29, 656-682. doi:10.1016/j.rser.2013.08.050

Bashir, M., Yu, X., Hassan, M., and Makkawi, Y. (2017). Modeling and Performance Analysis of Biomass Fast Pyrolysis in a Solar-thermal Reactor. ACS Sust. Chem. Eng. 5 (5), 3795-3807. doi:10.1021/acssuschemeng.6b02806 
Bhosale, R., Kumar, A., AlMomani, F., and Gupta, R. B. (2017). Solar Thermochemical $\mathrm{ZnO} / \mathrm{ZnSO} 4$ Water Splitting Cycle for Hydrogen Production. Int. J. Hydrogen Energ. 42 (37), 23474-23483. doi:10.1016/j.ijhydene.2017.02.190

Bhosale, R. R. (2019). Thermochemical H2 Production via Solar Driven Hybrid SrO/SrSO4 Water Splitting Cycle. Int. J. Hydrogen Energ. 44 (1), 118-127. doi:10.1016/j.ijhydene.2018.02.053

Binotti, M., Di Marcoberardino, G., Biassoni, M., and Manzolini, G. (2017). Solar Hydrogen Production With Cerium Oxides Thermochemical Cycle". In AIP Conference Proceedings (AIP Publishing LLC), 100002.

Boretti, A. (2021). Technology Readiness Level of Solar Thermochemical Splitting Cycles. ACS Energ. Lett. 6 (4), 1170-1174. doi:10.1021/acsenergylett.1c00181

Boujjat, H., Yuki Junior, G. M., Rodat, S., and Abanades, S. (2020). Dynamic Simulation and Control of Solar Biomass Gasification for Hydrogen-Rich Syngas Production during Allothermal and Hybrid Solar/autothermal Operation. Int. J. Hydrogen Energ. 45 (48), 25827-25837. doi:10.1016/ j.ijhydene.2020.01.072

Bulfin, B., Ackermann, S., Furler, P., and Steinfeld, A. (2021). Thermodynamic Comparison of Solar Methane Reforming via Catalytic and Redox Cycle Routes. Solar Energy 215, 169-178.

Bulfin, B., Lange, M., de Oliveira, L., Roeb, M., and Sattler, C. (2016). Solar Thermochemical Hydrogen Production Using Ceria Zirconia Solid Solutions: Efficiency Analysis. Int. J. Hydrogen Energ. 41 (42), 19320-19328. doi:10.1016/ j.ijhydene.2016.05.211

Bulfin, B., Vieten, J., Agrafiotis, C., Roeb, M., and Sattler, C. (2017). Applications and Limitations of Two Step Metal Oxide Thermochemical Redox Cycles; a Review. J. Mater. Chem. A. 5 (36), 18951-18966. doi:10.1039/c7ta05025a

Chuayboon, S., Abanades, S., Rodat, S., and Boujjat, H. (2019). "Experimental Assessment of Biomass Feedstock Gasification in a High-Temperature Continuous Solar Gasifier," in AIP Conference Proceedings (AIP Publishing LLC, Casablanca, Morocco, October 2-5, 2018), 180006. doi:10.1016/ j.solener.2020.11.076

Chuayboon, S., Abanades, S., and Rodat, S. (2019a). Syngas Production via SolarDriven Chemical Looping Methane Reforming from Redox Cycling of Ceria Porous Foam in a Volumetric Solar Reactor. Chem. Eng. J. 356, 756-770. doi:10.1016/j.cej.2018.09.072

Di Blasi, C., Branca, C., and Galgano, A. (2017). On the Experimental Evidence of Exothermicity in Wood and Biomass Pyrolysis. Energy Technol. 5 (1), 19-29.

Ermanoski, I., Miller, J. E., and Allendorf, M. D. (2014). Efficiency Maximization in Solar-Thermochemical Fuel Production: Challenging the Concept of Isothermal Water Splitting. Phys. Chem. Chem. Phys. 16 (18), 8418-8427. doi:10.1039/c4cp00978a

Ermanoski, I., Siegel, N. P., and Stechel, E. B. (2013). A New Reactor Concept for Efficient Solar-Thermochemical Fuel Production. J. Solar Energ. Eng. 135 (3), 031002. doi:10.1115/1.4023356

Falter, Christoph. (2017). Efficiency Potential of Solar Thermochemical Reactor Concepts with Ecological and Economical Performance Analysis of Solar Fuel Production. Aachen, Germany: Diss. RWTH Aachen. doi:10.18154/RWTH2017-06526

Falter, C. P., and Pitz-Paal, R. (2017). A Generic Solar-Thermochemical Reactor Model with Internal Heat Diffusion for Counter-flow Solid Heat Exchange. Solar Energy 144, 569-579. doi:10.1016/j.solener.2017.01.063

Fletcher, E. A., and Moen, R. L. (1977). Hydrogen- and Oxygen from Water. Science 197 (4308), 1050-1056. doi:10.1126/science.197.4308.1050

Fosheim, J. R., Hathaway, B. J., and Davidson, J. H. (2019). High Efficiency Solar Chemical-Looping Methane Reforming with Ceria in a Fixed-Bed Reactor. Energy 169, 597-612. doi:10.1016/j.energy.2018.12.037

Gokon, N., Izawa, T., Abe, T., and Kodama, T. (2014). Steam Gasification of Coal Cokes in an Internally Circulating Fluidized Bed of thermal Storage Material for Solar Thermochemical Processes. Int. J. Hydrogen Energ. 39 (21), 11082-11093. doi:10.1016/j.ijhydene.2014.05.124

Haeussler, A., Abanades, S., Julbe, A., Jouannaux, J., and Cartoixa, B. (2020). Solar Thermochemical Fuel Production from $\mathrm{H} 2 \mathrm{O}$ and $\mathrm{CO} 2$ Splitting via Two-step Redox Cycling of Reticulated Porous Ceria Structures Integrated in a Monolithic Cavity-type Reactor. Energy 201, 117649. doi:10.1016/ j.energy.2020.117649

Hathaway, B. J., Bala Chandran, R., Gladen, A. C., Chase, T. R., and Davidson, J. H. (2016). Demonstration of a Solar Reactor for Carbon Dioxide Splitting via the
Isothermal Ceria Redox Cycle and Practical Implications. Energy Fuels 30 (8), 6654-6661. doi:10.1021/acs.energyfuels.6b01265

Hathaway, B. J., and Davidson, J. H. (2017). Demonstration of a Prototype Molten Salt Solar Gasification Reactor. Solar Energy 142, 224-230. doi:10.1016/ j.solener.2016.12.032

Hoskins, A. L., Millican, S. L., Czernik, C. E., Alshankiti, I., Netter, J. C., Wendelin, T. J., et al. (2019). Continuous On-Sun Solar Thermochemical Hydrogen Production via an Isothermal Redox Cycle. Appl. Energ. 249, 368-376. doi:10.1016/j.apenergy.2019.04.169

Jarrett, C., Chueh, W., Yuan, C., Kawajiri, Y., Sandhage, K. H., and Henry, A. (2016). Critical Limitations on the Efficiency of Two-Step Thermochemical Cycles. J. Sol. Energy 123, 57-73.

Jin, J., Wei, X., Liu, M., Yu, Y., Li, W., Kong, H., et al. (2018). A Solar Methane Reforming Reactor Design with Enhanced Efficiency. Appl. Energ. 226, 797-807. doi:10.1016/j.apenergy.2018.04.098

Kodama, T. (2003). High-temperature Solar Chemistry for Converting Solar Heat to Chemical Fuels. Prog. Energ. combustion Sci. 29 (6), 567-597. doi:10.1016/ s0360-1285(03)00059-5

Koepf, E., Villasmil, W., and Meier, A. (2016). Pilot-scale Solar Reactor Operation and Characterization for Fuel Production via the $\mathrm{Zn} / \mathrm{ZnO}$ Thermochemical Cycle. Appl. Energ. 165, 1004-1023. doi:10.1016/j.apenergy.2015.12.106

Kong, H., Hao, Y., and Jin, H. (2018). Isothermal versus Two-Temperature Solar Thermochemical Fuel Synthesis: A Comparative Study. Appl. Energ. 228, 301-308. doi:10.1016/j.apenergy.2018.05.099

Kong, H., Hao, Y., and Wang, H. (2016). A Solar Thermochemical Fuel Production System Integrated with Fossil Fuel Heat Recuperation. Appl. Therm. Eng. 108, 958-966. doi:10.1016/j.applthermaleng.2016.03.170

Lange, J.-P. (2016). Catalysis for Biorefineries - Performance Criteria for Industrial Operation. Catal. Sci. Technol. 6 (13), 4759-4767. doi:10.1039/c6cy00431h

Lapp, J., Davidson, J. H., and Lipiński, W. (2012). Efficiency of Two-step Solar Thermochemical Non-stoichiometric Redox Cycles with Heat Recovery. Energy 37 (1), 591-600. doi:10.1016/j.energy.2011.10.045

Levenspiel, O. (2001). Chemical Reaction Engineering. 3rd edition. New York, NY: John Willey and Sons.

Li, S., Wheeler, V. M., Kumar, A., Venkataraman, M. B., Muhich, C. L., Hao, Y., et al. (2021). Thermodynamic Guiding Principles for Designing Nonstoichiometric Redox Materials for Solar Thermochemical Fuel Production: Ceria, Perovskites, and beyond. Energ. Tech., 2000925. doi:10.1002/ente.202000925

Loutzenhiser, P. G., and Muroyama, A. P. (2017). A Review of the State-Of-TheArt in Solar-Driven Gasification Processes with Carbonaceous Materials. Solar Energy 156, 93-100. doi:10.1016/j.solener.2017.05.008

Lu, Y., Zhu, L., Agrafiotis, C., Vieten, J., Roeb, M., and Sattler, C. (2019). Solar Fuels Production: Two-step Thermochemical Cycles with Cerium-Based Oxides. Prog. Energ. Combustion Sci. 75, 100785. doi:10.1016/j.pecs.2019.100785

Maag, G., Zanganeh, G., and Steinfeld, A. (2009). Solar thermal Cracking of Methane in a Particle-Flow Reactor for the Co-production of Hydrogen and Carbon. Int. J. Hydrogen Energ. 34 (18), 7676-7685. doi:10.1016/j.ijhydene.2009.07.037

Mao, Y., Gao, Y., Dong, W., Wu, H., Song, Z., Zhao, X., et al. (2020). Hydrogen Production via a Two-step Water Splitting Thermochemical Cycle Based on Metal Oxide - A Review. Appl. Energ. 267, 114860. doi:10.1016/ j.apenergy.2020.114860

Marxer, D., Furler, P., Takacs, M., and Steinfeld, A. (2017). Solar Thermochemical Splitting of $\mathrm{CO} 2$ into Separate Streams of $\mathrm{CO}$ and $\mathrm{O} 2$ with High Selectivity, Stability, Conversion, and Efficiency. Energy Environ. Sci. 10 (5), 1142-1149. doi:10.1039/c6ee $03776 \mathrm{c}$

Muhich, C. L., Evanko, B. W., Weston, K. C., Lichty, P., Liang, X., Martinek, J., et al. (2013). Efficient Generation of $\mathrm{H} 2$ by Splitting Water with an Isothermal Redox Cycle. Science 341 (6145), 540-542. doi:10.1126/science.1239454

Müller, F., Patel, H., Blumenthal, D., Poživil, P., Das, P., Wieckert, C., et al. (2018). Co-production of Syngas and Potassium-Based Fertilizer by Solar-Driven Thermochemical Conversion of Crop Residues. Fuel Process. Tech. 171, 89-99. doi:10.1016/j.fuproc.2017.08.006

Müller, F., Poživil, P., Van Eyk, P. J., Villarrazo, A., Haueter, P., Wieckert, C., et al. (2017). A Pressurized High-Flux Solar Reactor for the Efficient Thermochemical Gasification of Carbonaceous Feedstock. Fuel 193, 432-443. doi:10.1016/j.fuel.2016.12.036 
Muroyama, A. P., Guscetti, I., Schieber, G. L., Haussener, S., and Loutzenhiser, P. G. (2018). Design and Demonstration of a Prototype $1.5 \mathrm{~kW}$ th Hybrid Solar/ autothermal Steam Gasifier. Fuel 211, 331-340. doi:10.1016/j.fuel.2017.09.059

Noring, J. E., and Fletcher, E. A. (1982). High Temperature Solar Thermochemical Processing-Hydrogen and Sulfur from Hydrogen Sulfide. Energy 7 (8), 651-666. doi:10.1016/0360-5442(82)90002-0

Nzihou, A., Flamant, G., and Stanmore, B. (2012). Synthetic Fuels from Biomass Using Concentrated Solar Energy - A Review. Energy 42 (1), 121-131. doi:10.1016/j.energy.2012.03.077

Ozin, G. (2018). Drop-In Solar Fuels from Carbon Dioxide and Water: Performance Indicators. Available at: https://www.advancedsciencenews.com/drop-in-solarfuels-from-carbon-dioxide-and-water-performance-indicators.

Palumbo, A. W., Sorli, J. C., and Weimer, A. W. (2015). High Temperature Thermochemical Processing of Biomass and Methane for High Conversion and Selectivity to H2-Enriched Syngas. Appl. Energ. 157, 13-24. doi:10.1016/ j.apenergy.2015.07.072

Piatkowski, N., Wieckert, C., Weimer, A. W., and Steinfeld, A. (2011). Solar-Driven Gasification of Carbonaceous Feedstock-A Review . Energy Environ. Sci. 4 (1), 73-82.

Rodat, S., Abanades, S., Boujjat, H., and Chuayboon, S. (2020). On the Path toward Day and Night Continuous Solar High Temperature Thermochemical Processes: A Review. Renew. Sust. Energ. Rev. 132, 110061. doi:10.1016/ j.rser.2020.110061

Rodat, S., Abanades, S., and Flamant, G. (2011). Co-production of Hydrogen and Carbon Black from Solar thermal Methane Splitting in a Tubular Reactor Prototype. Solar energy 85 (4), 645-652. doi:10.1016/j.solener.2010.02.016

Romero, M., and Steinfeld, A. (2012). Concentrating Solar Thermal Power and Thermochemical Fuels. Energ. Environ. Sci. 5, 9234-9245. doi:10.1039/c2ee21275g

Safari, F., and Dincer, I. (2020). A Review and Comparative Evaluation of Thermochemical Water Splitting Cycles for Hydrogen Production. Energ. Convers. Manag. 205, 112182. doi:10.1016/j.enconman.2019.112182

Sheu, E. J., Mokheimer, E. M. A., and Ghoniem, A. F. (2015). A Review of Solar Methane Reforming Systems. Int. J. Hydrogen Energ. 40 (38), 12929-12955. doi:10.1016/j.ijhydene.2015.08.005

Singh, A., Lapp, J., Grobbel, J., Brendelberger, S., Reinhold, J. P., Olivera, L., et al. (2017). Design of a Pilot Scale Directly Irradiated, High Temperature, and Low Pressure Moving Particle Cavity Chamber for Metal Oxide Reduction. Solar Energy 157, 365-376. doi:10.1016/j.solener.2017.08.040

Steinfeld, A.. (2014) Solar Thermochemical Production of Hydrogen. in Handbook of Hydrogen Energy. Boca Raton, FL: CRC Press, Chapter 12, 421-443.

Steinfeld, A. (2012). Thermochemical Production of Syngas Using Concentrated Solar Energy. Annu. Rev. Heat Transfer 15. doi:10.1615/annualrevheattransfer.2012004537
Welte, M., Barhoumi, R., Zbinden, A., Scheffe, J. R., and Steinfeld, A. (2016) Experimental Demonstration of the Thermochemical Reduction of Ceria in a Solar Aerosol Reactor. Ind. Eng. Chem. Res. 55 (40), 10618-10625. doi:10.1021/ acs.iecr.6b02853

Yadav, D., and Banerjee, R. (2016). A Review of Solar Thermochemical Processes. Renew. Sust. Energ. Rev. 54, 497-532. doi:10.1016/j.rser.2015.10.026

Yuan, C., Jarrett, C., Chueh, W., Kawajiri, Y., and Henry, A. (2015). A New Solar Fuels Reactor Concept Based on a Liquid Metal Heat Transfer Fluid: Reactor Design and Efficiency Estimation. Solar Energy 122, 547-561. doi:10.1016/ j.solener.2015.08.019

Z’Graggen, A., Haueter, P., Maag, G., Vidal, A., Romero, M., and Steinfeld, A. (2006). "Hydrogen Production by Steam-Gasification of Petroleum Coke Using Concentrated Solar Power: Reactor Experimentation with Slurry Feeding”. In International Solar Energy Conference, Denver, CO, July 8-13, 2006 (ASME). 23-27. doi:10.1115/ISEC2006-99029

Z'Graggen, A., and Steinfeld, A. (2008). Hydrogen Production by Steam-Gasification of Carbonaceous Materials Using Concentrated Solar Energy-V. Reactor Modeling, Optimization, and Scale-Up. Int. J. Hydrogen Energ. 33 (20), 5484-5492.

Zeng, K., Gauthier, D., Soria, J., Mazza, G., and Flamant, G. (2017). Solar Pyrolysis of Carbonaceous Feedstocks: A Review. Solar Energy 156, 73-92. doi:10.1016/ j.solener.2017.05.033

Zheng, R., Diver, R., Caldwell, D., Fritz, B., Cameron, R., Humble, P., et al. (2015). Integrated Solar Thermochemical Reaction System for Steam Methane Reforming. Energ. Proced. 69, 1192-1200. doi:10.1016/j.egypro.2015.03.204

Zhu, L., Lu, Y., and Shen, S. (2016). Solar Fuel Production at High Temperatures Using Ceria as a Dense Membrane. Energy 104, 53-63. doi:10.1016/ j.energy.2016.03.108

Zoller, S., Koepf, E., Roos, P., and Steinfeld, A. (2019). Heat Transfer Model of a $50 \mathrm{~kW}$ Solar Receiver-Reactor for Thermochemical Redox Cycling Using Cerium Dioxide. J. Solar Energ. Eng. 141 (2). doi:10.1115/1.4042059

Conflict of Interest: The authors declare that the research was conducted in the absence of any commercial or financial relationships that could be construed as a potential conflict of interest.

Copyright (C) 2021 Bulfin, Miranda and Steinfeld. This is an open-access article distributed under the terms of the Creative Commons Attribution License (CC BY). The use, distribution or reproduction in other forums is permitted, provided the original author(s) and the copyright owner(s) are credited and that the original publication in this journal is cited, in accordance with accepted academic practice. No use, distribution or reproduction is permitted which does not comply with these terms. 


\section{NOMENCLATURE}

$\eta$ Energy efficiency

$E_{\text {total }}$ Total energy demand

$Q$ Quantity of heat

$\dot{Q}$ Heat flow rate

$W$ Quantity of work

$\dot{W}$ Work flow rate

$n_{i}$ Number of moles of species $i$

$\dot{n}_{i}$ Molar flow rate of species $i$
$G_{i}$ Gibbs free energy of species $i$

$\mathrm{HHV}_{i}$ Higher heating value of species $i$

$X_{i}$ Conversion extent of reactant $i$

$S_{i}$ Selectivity towards product $i$

$Y_{i}$ Yield of product $i$

$\dot{n}_{i, 0}$ Input flow rate of species $i$

$\dot{n}_{i, f}$ Output flow rate of species $i$

$F_{i}$ Energy factor of component $i$

$U$ Upgrade factor of the heating value 